\begin{tabular}{|c|c|}
\hline Title & Solution plasma synthesis of Si nanoparticles \\
\hline Author(s) & Saito, Genki; Sakaguchi, Norihito \\
\hline Citation & $\begin{array}{l}\text { Nanotechnology, 26(23), 235602 } \\
\text { https://doi.org/10.1088/0957-4484/26/23/235602 }\end{array}$ \\
\hline Issue Date & $2015-05-20$ \\
\hline Doc URL & http:/hdl.handle.net/2115/61676 \\
\hline Rights & $\begin{array}{l}\text { This is an author-created, un-copyedited version of an article accepted for publication in Nanotechnology. The publisher } \\
\text { is not responsible for any errors or omissions in this version of the manuscript or any version derived from it. The } \\
\text { V ersion of Record is avai lable online at http://doi.org/10.1088/0957-4484/26/23/235602 }\end{array}$ \\
\hline Type & article (author version) \\
\hline File Information & GENKI_Si_ver7_plane.pdf \\
\hline
\end{tabular}

Instructions for use 


\title{
Solution plasma synthesis of Si nanoparticles
}

\author{
Genki Saito and Norihito Sakaguchi \\ Center for Advanced Research of Energy and Materials, Hokkaido \\ University, Sapporo 060-8628, Japan \\ E-mail: genki@eng.hokudai.ac.jp
}

\begin{abstract}
Silicon nanoparticles (Si-NPs) were directly synthesized from a Si bar electrode via a solution plasma. In order to produce smaller Si-NPs, the effects of different electrolytes and applied voltages on the product were investigated in the experiments detailed in this paper. The results demonstrated that the use of an acidic solution of $0.1 \mathrm{M} \mathrm{HCl}$ or $\mathrm{HNO}_{3}$ produced $\mathrm{Si}-\mathrm{NPs}$ without $\mathrm{SiO}_{2}$ formation. According to the TEM and electron energy-loss spectroscopy, the obtained Si-NPs contained both amorphous and polycrystalline Si particles, among which the smaller Si-NPs tended to be amorphous. When an alkaline solution of $\mathrm{K}_{2} \mathrm{CO}_{3}$ was used instead, amorphous $\mathrm{SiO}_{2}$ particles were synthesized owing to the corrosion of $\mathrm{Si}$ in the high-temperature environment. The $\mathrm{pH}$ values of $\mathrm{KCl}$ and $\mathrm{KNO}_{3}$ increased during electrolysis, and the products were partially oxidized in the alkaline solutions. The particle size increased with an increasing applied voltage because the excitation temperature of the plasma increased.
\end{abstract}

\section{Introduction}

Lithium-ion batteries (LIBs) have been widely used as energy-storage devices for applications such as portable electronic devices and electric vehicles. Current commercial LIBs, with graphite and other carbonaceous materials as standard anode materials, have a maximum theoretical capacity of $372 \mathrm{mAh} \cdot \mathrm{g}^{-1}$ because of the limited lithium storage sites within $\mathrm{sp}^{2}$-hybridized carbon hexahedrons corresponding to the intercalation of $\mathrm{Li}_{6} \mathrm{C}$. Among the new anode materials with higher capacities than those available commercially, silicon anodes have attracted much attention because of their high theoretical capacity of $3579 \mathrm{mAh} \cdot \mathrm{g}^{-1}$, allowing 
them to form a $\mathrm{Li}_{15} \mathrm{Si}_{4}$ alloy at room temperature [1-3]. During the lithium insertion-extraction process, however, a large volume change (>280\%) inevitably occurs, which leads to pulverization of the silicon anode and loss of electrical contact to the current collector, resulting in poor cycling performance $[2,4]$. To mitigate this volume-change issue, several strategies have been proposed, including reducing the particle size to nanoscale [5,6] and dispersing nano-Si in the conductive carbon matrix to form a Si-carbon composite [7-10]. Liu et al. (2012) reported that the critical particle diameter needs to be below $150 \mathrm{~nm}$ to avoid the surface cracking and subsequent fracturing during lithiation [4]. In addition, dispersing silicon nanoparticles (Si-NPs) into a carbon matrix is a technique that has been well developed, in which the carbonaceous material acts as a buffer to the volume expansion and improves the electrical conductivity of $\mathrm{Si}$ active materials [7].

To produce nanomaterials, various types of solution plasma have been employed [11-17]. The solution plasma technique offers many advantages, including (1) a simple experimental setup, (2) use of readily available precursors, (3) no requirement for harmful chemicals, (4) higher productivity than conventional solution processes, and (5) suitability for mass production. From the viewpoint of electrode configuration and power source, solution plasma techniques can be subdivided into four main groups:

(i) Gas discharge between an electrode and the electrolyte surface.

(ii) Direct discharge between two electrodes.

(iii) Contact discharge between an electrode and the surface of the surrounding electrolyte.

(iv) Radio frequency (RF) and microwave (MW) plasma in liquid.

For $\mathrm{Si}$ nanoparticle synthesis, Tokushige et al. reported the plasma-induced cathodic discharge electrolysis, in which the plasma was generated above the electrolyte surface in the Ar atmosphere (group i) [18]. The arc discharge in liquid has been applied to synthesize $\mathrm{Si}$ nanowire and Si-NPs, in which the distance between two Si electrodes was approximately $1 \mathrm{~mm}$ (group ii) $[19,20]$. Recently, contact glow discharge electrolysis (CGDE) was also used to synthesize Si-NPs (group iii) [16, 21]. In CGDE, the plasma is generated surrounding the electrode in the conductive electrolyte. In comparison to the arc discharge, the current was relatively small under a high voltage. Since lower current led to a decrease in electrode temperature, the Sn nanoparticles were produced using CGDE to improve the capacity of LIBs $[22,23]$. In this study, we investigated the effect of the electrolyte and the applied voltage on the product in order to fabricate smaller Si-NPs by solution plasma with CGDE. To study the plasma properties, the light emission of plasma was analyzed using spectroscopy. The obtained particles were characterized by scanning electron microscopy (SEM), transmission electron microscopy (TEM), and electron energy-loss spectroscopy (EELS). 


\section{Experimental}

Figure 1 shows the experimental setup for producing Si particles. A B-doped square-cross section Si bar with a width of $5.0 \mathrm{~mm}$ (Shin-Etsu Chemical Co., Ltd.), and an electric resistance of $0.00494-0.00478 \Omega \cdot \mathrm{cm}$ was used as the cathode. It was placed in a glass cell with a cooling jacket, and the upper part of the Si bar was shielded by a quartz glass tube to generate a plasma at the bottom tip of the electrode. A voltage was applied using a direct current power supply (ZX800H, Takasago). To study the effect of different electrolytes, 300-mL solutions of $0.1 \mathrm{M}$ $\mathrm{K}_{2} \mathrm{CO}_{3}, \mathrm{KCl}, \mathrm{KNO}_{3}, \mathrm{HCl}$, and $\mathrm{HNO}_{3}$ were used in separate experiments. The voltage was varied at three different levels for each electrolyte, as shown in table 1 . The high voltage corresponds to the maximum voltage that can be safely applied to the plasma over a long period. The low voltage corresponds to the voltage level used to initiate plasma generation with light emission. Before electrolysis, the solution was heated to a temperature above $60{ }^{\circ} \mathrm{C}$. During electrolysis, the solution was stirred using a magnetic stirrer at a rate of $300 \mathrm{rpm}$, and the plasma was generated for $1 \mathrm{~h}$. The light emission from the plasma was measured using a visible-light spectrophotometer (USB 2000+, Ocean Optics). After the synthesis, the products were collected by centrifugation and then washed several times with deionized water. The products were then characterized using a scanning electron microscope (JSM-7001FA, JEOL) and a field-emission transmission electron microscope (JEM-2010F, JEOL) with an EELS detector. 


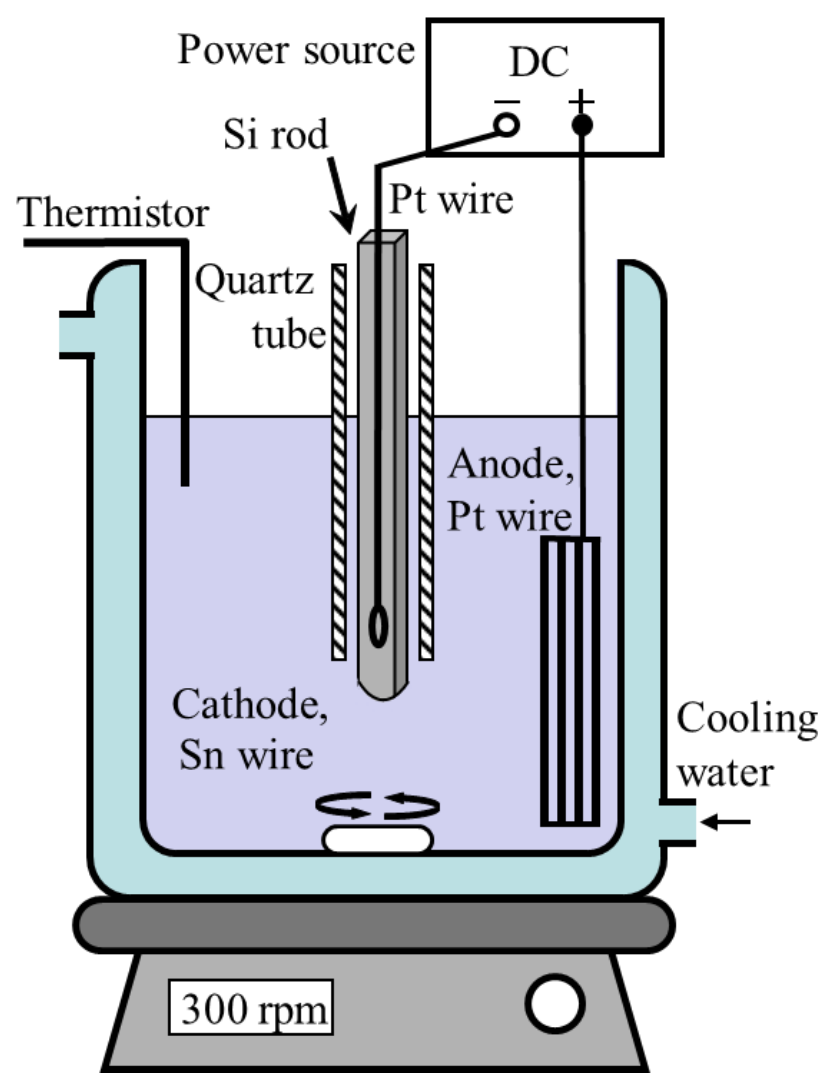

Figure 1. (color online) Experimental setup for producing Si particles. A Si rod electrode was placed in a glass cell with a cooling jacket, in which the upper part of the Si rod was shielded by a quartz glass tube to generate plasma at the bottom tip of the electrode.

Table 1. Applied voltage at each electrolyte.

\begin{tabular}{lrrrrr}
\hline Voltage $(\mathrm{V})$ & $\mathrm{K}_{2} \mathrm{CO}_{3}$ & $\mathrm{KCl}$ & $\mathrm{HCl}$ & $\mathrm{KNO}_{3}$ & $\mathrm{HNO}_{3}$ \\
\hline High voltage & 200 & 230 & 200 & & \\
Middle voltage & 180 & 210 & 180 & 230 & 160 \\
Low voltage & 160 & 190 & 160 & 210 & 140 \\
\hline
\end{tabular}

\section{Results and discussions}

\subsection{Plasma generation}

The discharge plasma with light emission was generated around the Si electrode at various voltage levels shown in table 1 . Figure 2 shows the typical current-voltage curve in the $0.1 \mathrm{M}$ $\mathrm{HCl}$ solution. When the voltage was increased, the current first increased and then decreased. Below 1.3 V, no current flowed because the electrolysis of water did not occur. The linear current increase with voltage, in accordance with Ohm's law, corresponds to the occurrence of electrolysis of water. Since the thermal loss was concentrated at the cathode-solution interface, 
the solution near the Si electrode was heated to the boiling point and a gas layer consisting of steam was generated. Once the gas layer was generated at the surface of the cathode, the cathode and the solution were no longer in contact with each other and the current decreased. When the voltage was sufficiently high $(>150 \mathrm{~V})$, a discharge with intense light emission began in the gas layer. In our experiments, the voltage was set to three different levels, namely 'low', 'middle', and 'high'. The plasma generation was continued at $1 \mathrm{~h}$ to produce nanoparticles.

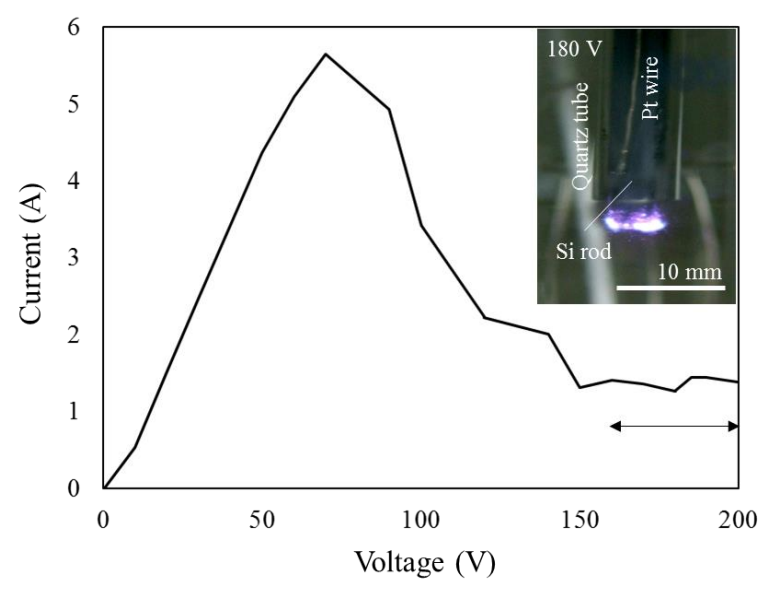

Figure 2. (color online) Current-voltage curve in $0.1 \mathrm{M} \mathrm{HCl}$ solution. Above $150 \mathrm{~V}$, plasma generation with light emission occurred and the intensity of the light emission increased with increases in voltage. The inset shows a photograph of the electrode at $180 \mathrm{~V}$.

To characterize the generated plasma, the light emission spectra were obtained by an optical fibre spectrometer. Figure 3(a) shows the spectra from the electrode in different electrolytes, in which the spectra contained emissions of the $\mathrm{OH} \mathrm{A}^{2} \Sigma^{+}-\mathrm{X}^{2} \Pi(0,0)$ band $(309 \mathrm{~nm}), \mathrm{H}_{\alpha}(656 \mathrm{~nm})$ and $\mathrm{H}_{\beta}(486 \mathrm{~nm})$ as the Balmer atomic hydrogen lines, and $\mathrm{O}(777 \mathrm{~nm})$. The emission lines at $385,413,505$, and $635 \mathrm{~nm}$ correspond to $\mathrm{Si} \mathrm{II}$ as an electrode material. When $\mathrm{KCl}, \mathrm{KNO}_{3}$, or $\mathrm{K}_{2} \mathrm{CO}_{3}$ were used as the electrolyte, strong emission of $\mathrm{K}(769.9$ and $766.5 \mathrm{~nm})$ was detected. These results agree with those reported for other solution plasmas [14, 24]. The excitation temperature was calculated from the Boltzmann plot by assuming local thermodynamic equilibrium (LTE) [25] as follows:

$$
\ln \left(\frac{I_{i j} \lambda_{i j}}{g_{i} A_{i j}}\right)=-\frac{E_{i}}{k T}+\ln \left(\frac{N(T)}{U(T)}\right),
$$

where $I_{i j}$ is the emission intensity of $\mathrm{H}_{\alpha}(656 \mathrm{~nm})$ and $\mathrm{H}_{\beta}(486 \mathrm{~nm}), \lambda_{i j}$ is the wavelength, $g_{i}$ is the statistical weight of the upper level, $A_{i j}$ is the transition probability, $E_{i}$ is the upper level 
energy, $k$ is the Boltzmann constant, $N(T)$ is the total number density of neutrals, and $U(T)$ is the partition function. Figure 3(b) shows the excitation temperatures calculated for different electrolytes and applied voltages. The higher applied voltage excited the plasma and the excitation temperatures ranged from 4500 to $7000 \mathrm{~K}$. Compared to other solution plasmas, this value is relatively high. In the case of a microwave plasma and a high-frequency plasma in a liquid [25-27], for example, the excitation temperatures ranged from approximately 3000 to $5500 \mathrm{~K}$. In our plasma, the net area of discharge was considered to be low and the plasma was generated at current concentration spots. Therefore, the average temperature of the electrode surface was low. However, the average temperature of Si electrode is still higher than that of conventional metal electrodes because of the higher electric resistance of $\mathrm{Si}$ and the higher surface temperature excited the plasma.
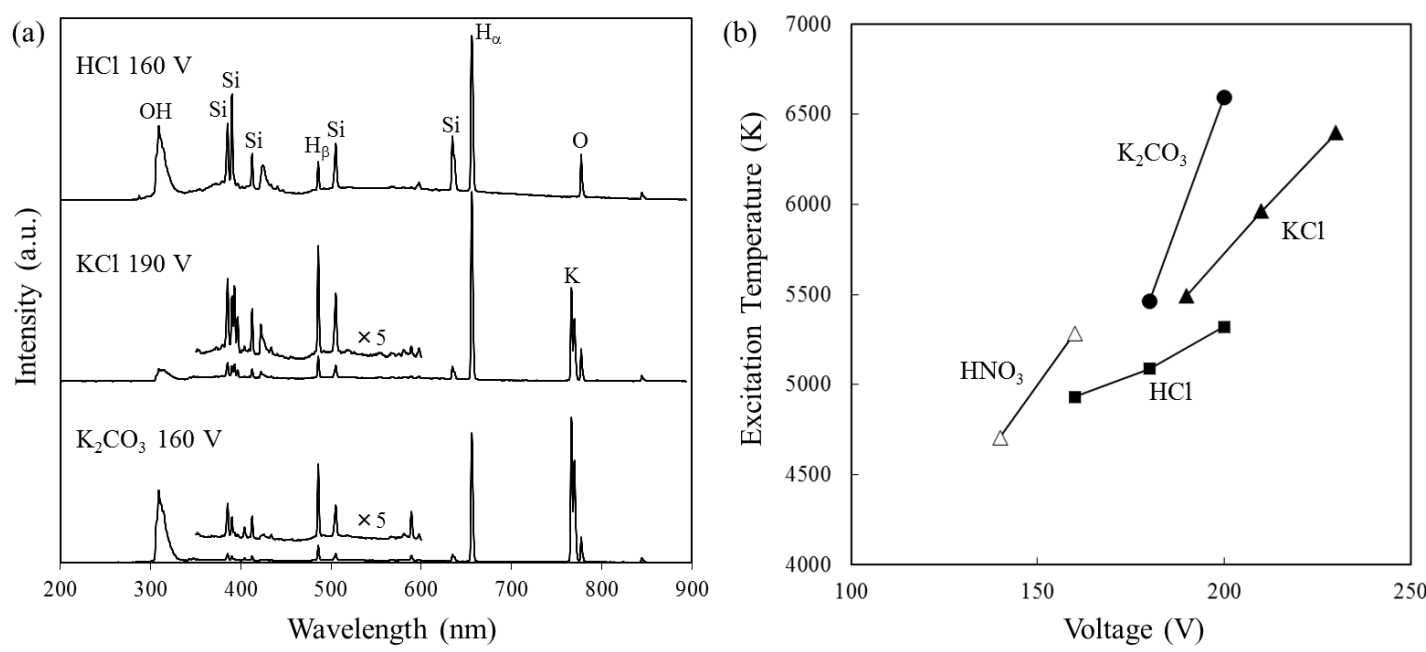

Figure 3. (a) Spectra of the electrode in different electrolytes. (b) Excitation temperature versus applied voltage in different electrolytes. The excitation temperatures were calculated from the intensity of the light emission of $\mathrm{H}_{\alpha}(656.3 \mathrm{~nm})$ and $\mathrm{H}_{\beta}(486.1 \mathrm{~nm})$ when the electrons were assumed to have a Boltzmann distribution.

\subsection{Characterization of the synthesis products}

The produced particles were dispersed in a solution, and a cooling jacket was used to reduce the solution temperature to below $70{ }^{\circ} \mathrm{C}$. The products obtained from the plasma electrolysis were collected by centrifugation and characterized by SEM. As shown in the SEM image (figure 4), the products synthesized in different electrolytes at different applied voltages were spherical in shape. Various spots of the Si bar was partially melted or ionized by the plasma and then immediately solidified to form spherical particles. For each electrolyte, a higher applied 
voltage increased the particle size because of the higher excitation temperature. When the applied voltage was low, the particle size decreased to less than $1 \mu \mathrm{m}$. When $\mathrm{KCl}$ and $\mathrm{K}_{2} \mathrm{CO}_{3}$ solutions were used as the electrolyte, the respective products contained thin film-like particles, which might be a corrosion product precipitated during the drying process. The average current and electrode consumption are summarized in Fig. 5. At each electrolyte, the current decreased with an increase in the applied voltage. When the applied voltage was increased, a thick gas layer formed that prevented current flow. To estimate the amount of particles produced, the difference between the electrode weights before and after the experiments was measured, as shown in Fig. 5(b). In the case of $180 \mathrm{~V}$ in $0.1 \mathrm{M} \mathrm{HCl}$ solution, $17.8 \mathrm{mg}$ of the product was produced during $1 \mathrm{~h}$ with an applied electric power of $180 \mathrm{Wh}$. When the discharge area is increased and discharge continues, the production rate will increase.
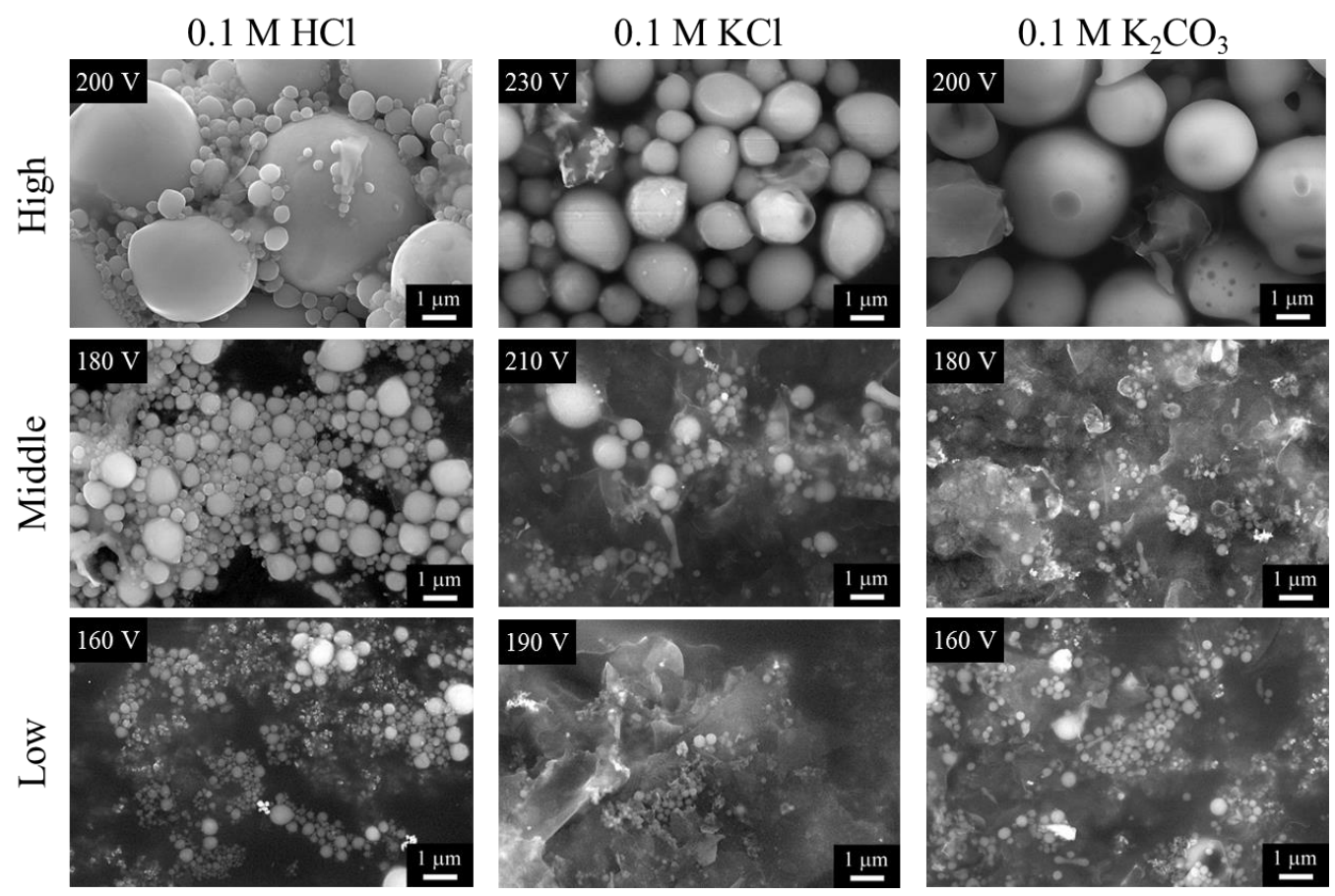

Figure 4. SEM image of Si particles produced in different electrolytes at different applied voltages. 

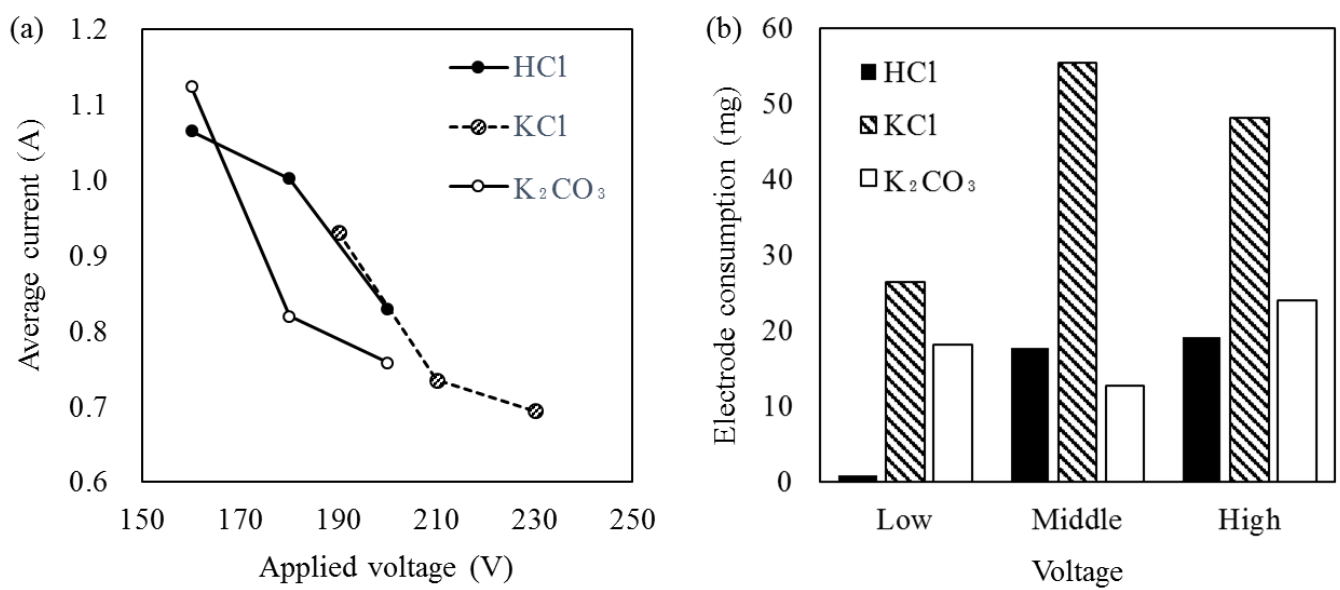

Figure 5 (a) Relationship between the applied voltage and average current for different electrolytes. (b) Electrode consumption at different conditions.

Based on TEM observation of the particles shown in figure 5, they were classified into 4 types: (a) single crystalline $\mathrm{Si}$, (b) polycrystalline $\mathrm{Si}$, (c) amorphous-like $\mathrm{Si}$, and (d) amorphous $\mathrm{SiO}_{2}$. The product phase strongly depended on the electrolyte used. When acidic solutions of $\mathrm{HCl}$ and $\mathrm{HNO}_{3}$ were used as the electrolyte, the amorphous $\mathrm{SiO}_{2}$ particles were not detected. In contrast, the alkaline solution of $\mathrm{K}_{2} \mathrm{CO}_{3}$ produced only amorphous $\mathrm{SiO}_{2}$, in which no Si particles could be found. Diffraction patterns and EEL spectra of the four types of Si particles are also shown in figure 6. By analysing the energy-loss near-edge structure of Si-L $\mathrm{L}_{2,3}$ in EELS, the electronic structure of Si could be determined [28, 29]. In figure 6(a,b), the diffraction patterns and EEL spectra match those of Si. Amorphous Si-NPs were also formed, as shown in figure 5(c). Si-NPs were mainly synthesized when the acidic solutions of $\mathrm{HCl}$ and $\mathrm{HNO}_{3}$ were used, and crystalline structures were different owing to the difference in cooling rates during solidification. When the particles were immediately quenched, amorphous Si particles were generated. It is considered that the cooling rate increased in the following order: (a) single-crystalline $\mathrm{Si}<$ (b) polycrystalline $\mathrm{Si}<$ (c) amorphous-like $\mathrm{Si}$. The enlarged TEM image of the single-crystalline Si particle shown in Fig. 7 revealed that the oxide layer with a thickness of 3-4 $\mathrm{nm}$ existed on the Si surface. This oxide layer was generated during melting and solidification under a high-temperature atmosphere. Figure 6(d) shows amorphous $\mathrm{SiO}_{2}$ nanoparticles produced by the alkaline $\mathrm{K}_{2} \mathrm{CO}_{3}$ solution, whose EEL spectrum agrees with that of the $\mathrm{SiO}_{2}$ phase. When neutral solutions of $\mathrm{KCl}$ and $\mathrm{KNO}_{3}$ were used, both $\mathrm{Si}$ and $\mathrm{SiO}_{2}$ particles were produced. At certain hot spots on the electrode surface during the plasma electrolysis, the $\mathrm{Si}^{2+}$ ions were generated and they combined with $\mathrm{OH}^{-}$to form $\mathrm{SiO}_{2}: \mathrm{Si}^{2+}+2 \mathrm{OH}^{-} \rightarrow \mathrm{Si}(\mathrm{OH})_{2} \rightarrow$ 
$\mathrm{SiO}_{2}+\mathrm{H}_{2} \mathrm{O}$. Etching of $\mathrm{Si}$ in $\mathrm{KOH}$ and $\mathrm{NaOH}$ was also reported by other research groups [30, 31]. Thus, the $\mathrm{pH}$ value of the electrolyte might have affected the product phase.
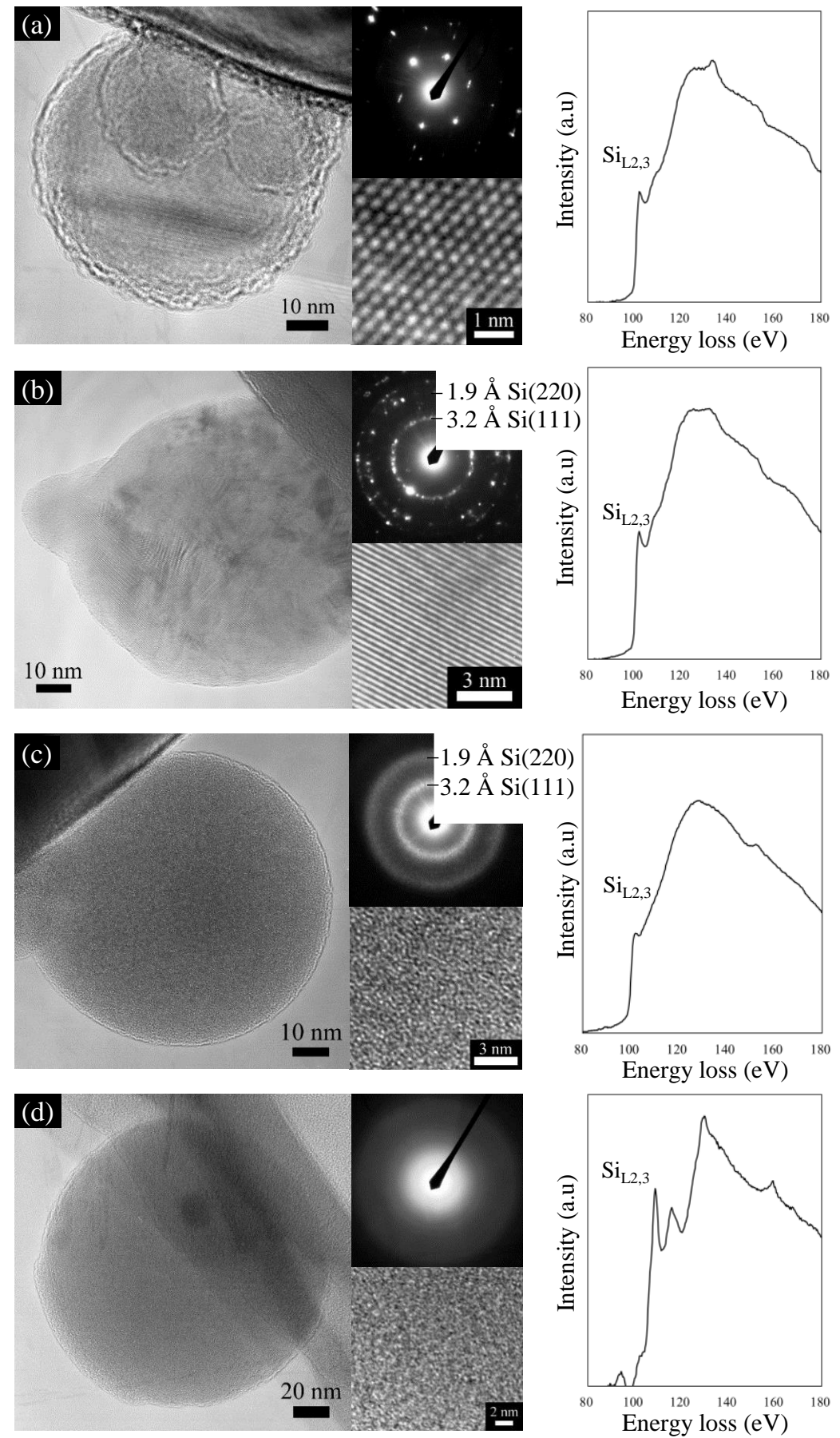

Figure 6. TEM images, diffraction patterns, and high-resolution TEM images of different types of (a) single-crystalline $\mathrm{Si}$, (b) polycrystalline $\mathrm{Si}$, (c) amorphous-like $\mathrm{Si}$, and (d) amorphous $\mathrm{SiO}_{2}$ nanoparticles. The graphs on the right side show the corresponding EEL spectra of the 
particles. The spectra of particles in $(\mathrm{a}-\mathrm{c})$ agree with those of $\mathrm{Si}$ and the amorphous particles in (d) were detected in $\mathrm{SiO}_{2}$.

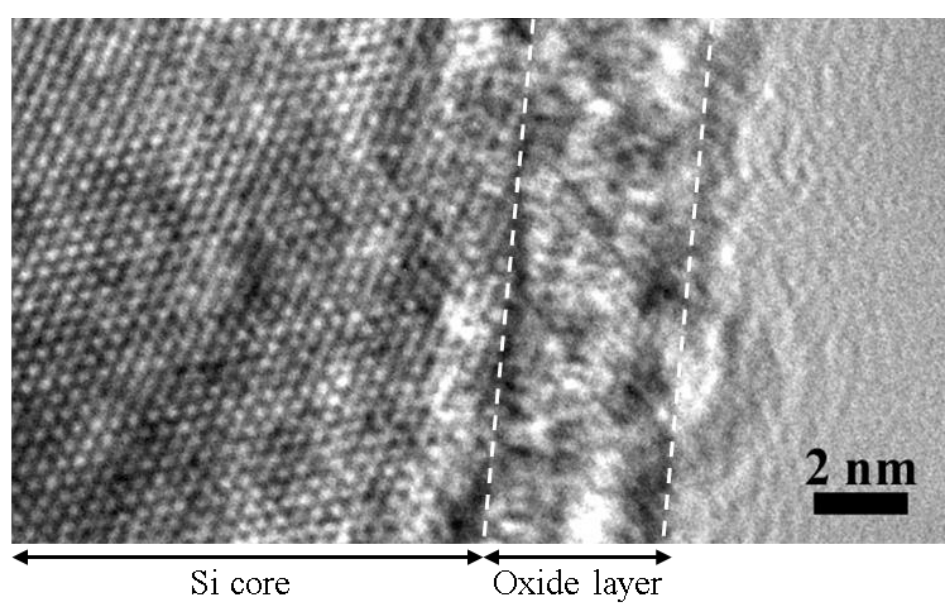

Figure 7. Enlarged TEM image of Si-NP produced in HNO3 solution. The oxide layer with a thickness of 3-4 nm was formed on the Si surface.

Figure 8 shows the change in $\mathrm{pH}$ during plasma electrolysis in different electrolytes. When the electrolyte was either a strong acid or strong base, the $\mathrm{pH}$ remained constant. The $\mathrm{pH}$ of $\mathrm{KNO}_{3}$ and $\mathrm{KCl}$ increased during electrolysis because of the consumption of negative ions and formation of $\mathrm{OH}^{-}$ions. In principle, the electrolysis of an acidic solution can be described as follows:

$$
2 \mathrm{H}_{2} \mathrm{O}=4 \mathrm{H}^{+}+\mathrm{O}_{2}(\mathrm{~g})+2 \mathrm{e}^{-}
$$

However, the reduction of $\mathrm{Cl}^{-}$ions was favoured over the decomposition of $\mathrm{H}_{2} \mathrm{O}$ :

$$
2 \mathrm{Cl}^{-}=\mathrm{Cl}_{2}(\mathrm{~g})+2 \mathrm{e}^{-}
$$

Therefore, the $\mathrm{pH}$ in the neutral solution increased owing to the generation of $\mathrm{Cl}_{2}$ gas, and oxide particles were then formed to react with the $\mathrm{OH}^{-}$ions, which produced $\mathrm{Cl}^{-}$ions instead. In the case of the $\mathrm{KNO}_{3}$ solution as the electrolyte, the reduction of $\mathrm{NO}_{3}{ }^{-}$to $\mathrm{NO}_{2}{ }^{-}$might occur at the cathode electrode [32].

$$
\mathrm{NO}_{3}{ }^{-}+2 \mathrm{e}^{-}+\mathrm{H}_{2} \mathrm{O}=\mathrm{NO}_{2}^{-}+2 \mathrm{OH}^{-}
$$

Table 2 summarizes the $\mathrm{pH}$ values and product compositions. After 2 weeks, the $\mathrm{pH}$ did not change considerably from the values after electrolysis. From these results, it is clear that the use of an acidic solution as the electrolyte was effective for producing Si-NPs. 


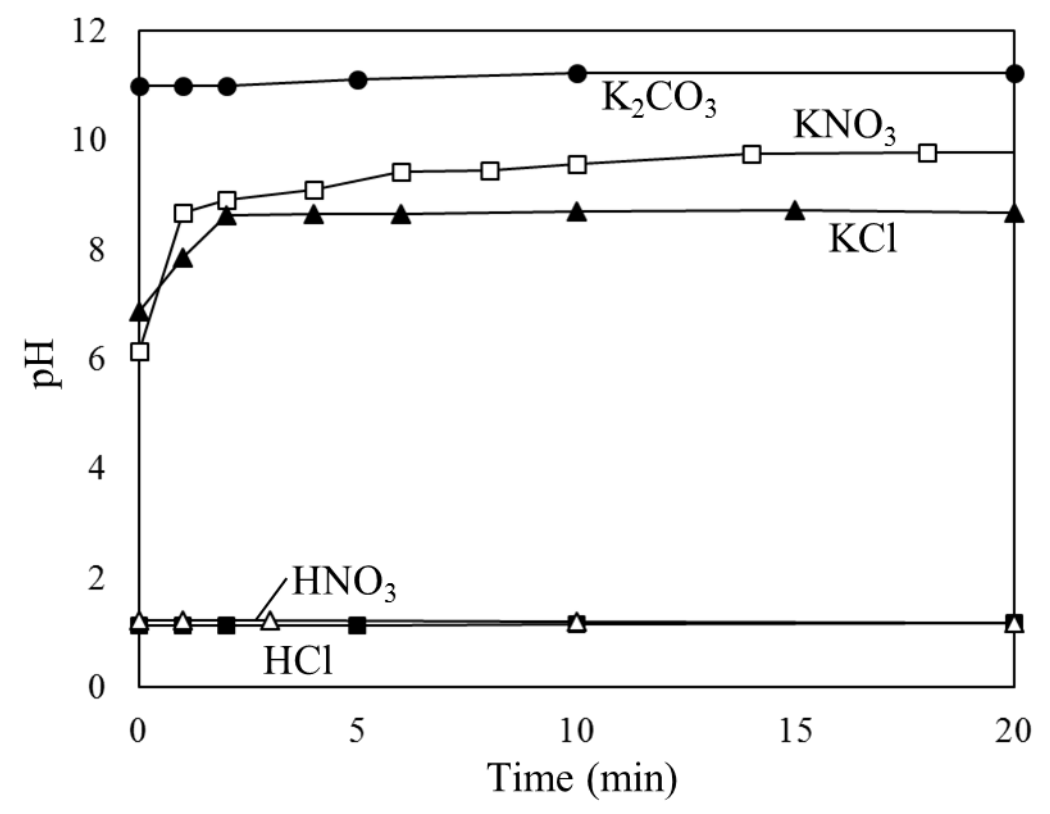

Figure 8. Changes in $\mathrm{pH}$ values during plasma electrolysis in different electrolytes. When the neutral solutions of $\mathrm{KNO}_{3}$ and $\mathrm{KCl}$ were used, the $\mathrm{pH}$ value was increased owing to the consumption of $\mathrm{Cl}^{-}$and $\mathrm{KNO}_{3}{ }^{-}$ions.

Table 2. $\mathrm{pH}$ values and product composition.

\begin{tabular}{lllll}
\hline Solution & $\begin{array}{l}\text { Initial } \mathrm{pH} \\
\text { value }\end{array}$ & $\begin{array}{l}\mathrm{pH} \text { value after } \\
\text { electrolysis }\end{array}$ & $\begin{array}{l}\mathrm{pH} \text { value after } 2 \\
\text { weeks }\end{array}$ & Products \\
\hline $0.1 \mathrm{M} \mathrm{K}_{2} \mathrm{CO}_{3}$ & 11.00 & 11.18 & 10.89 & $\mathrm{SiO}_{2}$ \\
\hline $0.1 \mathrm{M} \mathrm{KNO}_{3}$ & 6.13 & 9.88 & 9.87 & $\mathrm{Si}+\mathrm{SiO}_{2}$ \\
\hline $0.1 \mathrm{M} \mathrm{KCl}$ & 6.87 & 8.71 & 8.39 & $\mathrm{Si}+\mathrm{SiO}_{2}$ \\
\hline $0.1 \mathrm{M} \mathrm{HNO}$ & 1.21 & 1.10 & 1.06 & $\mathrm{Si}$ \\
\hline $0.1 \mathrm{M} \mathrm{HCl}$ & 1.12 & 1.24 & 1.23 & $\mathrm{Si}$ \\
\hline
\end{tabular}

Figure 9 shows the size distribution of particles obtained from plasma electrolysis in $0.1 \mathrm{M}$ $\mathrm{HNO}_{3}$ at an applied voltage of $140 \mathrm{~V}$. The 363 particles were analysed by TEM to distinguish the crystal structures. Most of the particles produced had diameters ranging from 50 to $100 \mathrm{~nm}$. The TEM analysis showed that the smaller particles with diameters below $100 \mathrm{~nm}$ contained the amorphous phase and the ratio of this amorphous phase increased with decreasing particle size. When the Si precursor of Si liquid, vapour, or ions was cooled immediately, amorphous Si-NPs 
were produced. In contrast, the coarse crystalline particles with diameters above $100 \mathrm{~nm}$ are believed to have been synthesized via solidification of the liquid silicon droplets generated on the Si electrode surface. When these Si-NPs are used for a battery anode, their crystalline structure might affect the battery performance. It is reported that the critical size for fracture is larger for amorphous Si spheres, and the lithiation reaction rate is approximately constant and does not slow as in the case of crystalline Si [33]. Therefore, amorphous Si nanoparticles are expected to more effectively prevent fracture during the first lithation cycle.

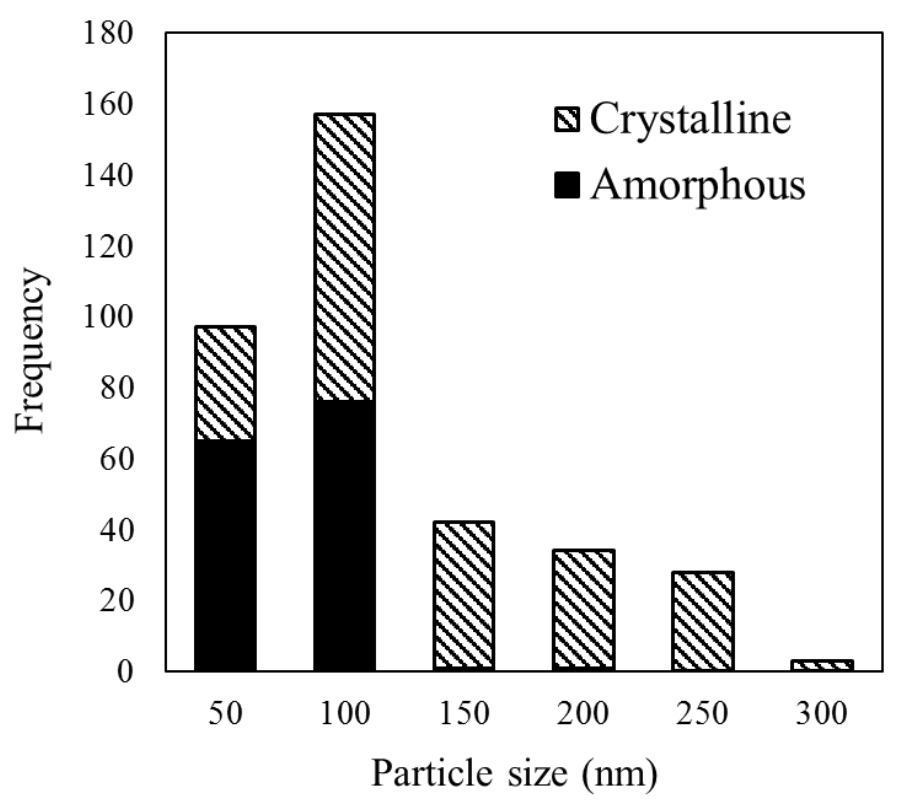

Figure 9. Size distribution of particles obtained by plasma electrolysis in $0.1 \mathrm{M} \mathrm{HNO}_{3}$ at an applied voltage of $140 \mathrm{~V}$. The 363 particles were analysed by TEM to distinguish the crystal structures. 


\section{Conclusions}

The solution plasma technique was used for the synthesis of Si-NPs. The plasma discharge was generated with light emission in various electrolytes, and evaluation of the Boltzmann plot showed that the excitation temperatures ranged from 4500 to $7000 \mathrm{~K}$. When the applied voltage was low, the excitation temperature and particle size were lower. The produced particle was characterized by TEM and EELS. Acidic solutions of $0.1 \mathrm{M} \mathrm{HCl}$ and $\mathrm{HNO}_{3}$ produced Si-NPs that contained both amorphous and polycrystalline particles, among which the smaller Si-NPs tended to be amorphous. When an alkaline solution of $\mathrm{K}_{2} \mathrm{CO}_{3}$ was used, amorphous $\mathrm{SiO}_{2}$ particles were synthesized owing to the etching of Si under the high-temperature alkaline atmosphere. Thus, the use of an acidic solution and low voltage were effective for producing smaller Si-NPs. The results will also offer insight into ways to produce Si-NPs easily and quickly. The prepared Si-NPs can be used to construct electrodes of lithium-ion batteries.

\section{Acknowledgments}

We would like to thank the "Nanotechnology Platform" Program of the Ministry of Education for allowing us to carry out transmission electron microscope observations on Si-NPs. This work was supported by a Grant-in-Aid for JSPS Fellows. The authors would like to thank Dr. Tomohiro Akiyama and Heishichiro Takahashi for many helpful discussions.

\section{References}

[1] Obrovac M N and Christensen L 2004 Structural Changes in Silicon Anodes during Lithium Insertion/Extraction Electrochemical and Solid-State Letters 7 A93-A6

[2] Kasavajjula U, Wang C and Appleby A J $2007 \mathrm{Nano}^{-}$and bulk-silicon-based insertion anodes for lithium-ion secondary cells Journal of Power Sources 163 1003-39

[3] Zhang W-J 2011 A review of the electrochemical performance of alloy anodes for lithium-ion batteries Journal of Power Sources 196 13-24

[4] Liu X H, Zhong L, Huang S, Mao S X, Zhu T and Huang J Y 2012 Size-Dependent Fracture of Silicon Nanoparticles During Lithiation ACS Nano 6 1522-31

[5] Xun S, Song X, Grass M E, Roseguo D K, Liu Z, Battaglia V S and Liu G 2011 Improved Initial Performance of Si Nanoparticles by Surface Oxide Reduction for Lithium-Ion Battery Application Electrochemical and Solid-State Letters 14 A61-A3

[6] Wu H, Zheng G, Liu N, Carney T J, Yang Y and Cui Y 2012 Engineering Empty Space between Si Nanoparticles for Lithium-Ion Battery Anodes Nano Letters 12 904-9

[7] Zhou M, Cai T, Pu F, Chen H, Wang Z, Zhang H and Guan S 2013 
Graphene/Carbon-Coated Si Nanoparticle Hybrids as High-Performance Anode Materials for Li-Ion Batteries ACS Applied Materials \& Interfaces 5 3449-55

[8] Gomez-Camer J L, Morales J and Sanchez L 2011 Anchoring Si nanoparticles to carbon nanofibers: an efficient procedure for improving Si performance in $\mathrm{Li}$ batteries Journal of Materials Chemistry 21 811-8

[9] Tao H-C, Fan L-Z, Mei Y and Qu X 2011 Self-supporting Si/Reduced Graphene Oxide nanocomposite films as anode for lithium ion batteries Electrochemistry Communications 13 1332-5

[10] Zhou M, Pu F, Wang Z, Cai T, Chen H, Zhang H and Guan S 2013 Facile synthesis of novel Si nanoparticles-graphene composites as high-performance anode materials for Li-ion batteries Physical Chemistry Chemical Physics 15 11394-401

[11] Kareem T and Kaliani A 2012 Glow discharge plasma electrolysis for nanoparticles synthesis Ionics 18 315-27

[12] Graham W G and Stalder K R 2011 Plasmas in liquids and some of their applications in nanoscience Journal of Physics D: Applied Physics 44174037

[13] Saito G, Nakasugi Y, Yamashita T and Akiyama T 2014 Solution plasma synthesis of bimetallic nanoparticles Nanotechnology 25135603

[14] Pootawang P, Saito N and Lee S Y 2013 Discharge time dependence of a solution plasma process for colloidal copper nanoparticle synthesis and particle characteristics Nanotechnology 24055604

[15] Sung-Pyo C, Maria Antoaneta B, Nagahiro S and Osamu T 2011 Microstructural characterization of gold nanoparticles synthesized by solution plasma processing Nanotechnology 22455701

[16] Yatsu S, Takahashi H, Sasaki H, Sakaguchi N, Ohkubo K, Muramoto T and Watanabe S 2013 Fabrication of Nanoparticles by Electric Discharge Plasma in Liquid. In: Archives of Metallurgy and Materials, p 425

[17] Toriyabe Y, Watanabe S, Yatsu S, Shibayama T and Mizuno T 2007 Controlled formation of metallic nanoballs during plasma electrolysis Applied Physics Letters $91041501-3$

[18] Tokushige M, Nishikiori T and Ito Y 2010 Plasma-induced cathodic discharge electrolysis to form various metal/alloy nanoparticles Russian Journal of Electrochemistry 46 619-26

[19] Liu S-M, Kobayashi M, Sato S and Kimura K 2005 Synthesis of silicon nanowires and nanoparticles by arc-discharge in water Chemical Communications 4690-2

[20] Kobayashi M, Liu S-M, Sato S, Yao H and Kimura K 2006 Optical Evaluation of Silicon Nanoparticles Prepared by Arc Discharge Method in Liquid Nitrogen 
Japanese Journal of Applied Physics 456146

[21] Azumi K, Kanada A, Kawaguchi M and Seo M 2005 Formation of microparticles from titanium and silicon electrodes using high-voltage discharge in electrolyte solution Hyomen gijutsu 56 938-41

[22] Saito G, Azman W O S B W M, Nakasugi Y and Akiyama T 2014 Optimization of electrolyte concentration and voltage for effective formation of $\mathrm{Sn} / \mathrm{SnO} 2$ nanoparticles by electrolysis in liquid Advanced Powder Technology 25 1038-42

[23] Saito G, Zhu C and Akiyama T 2014 Surfactant-assisted synthesis of Sn nanoparticles via solution plasma technique Advanced Powder Technology 25 728-32

[24] Greda K, Jamroz P and Pohl P 2013 Comparison of the performance of direct current atmospheric pressure glow microdischarges operated between a small sized flowing liquid cathode and miniature argon or helium flow microjets Journal of Analytical Atomic Spectrometry 28 1233-41

[25] Hattori Y, Mukasa S, Toyota H, Inoue T and Nomura S 2011 Continuous synthesis of magnesium-hydroxide, zinc-oxide, and silver nanoparticles by microwave plasma in water Materials Chemistry and Physics 131 425-30

[26] BRUGGEMAN, \#160, P., RIBEZL, E., DEGROOTE, J., VIERENDEELS, LEYS and C. 2008 Plasma characteristics and electrical breakdown between metal and water electrodes vol 10 (Bucuresti: INOE 2000)

[27] Nomura S, Toyota H, Mukasa S, Takahashi Y, Maehara T, Kawashima A and Yamashita H 2008 Discharge Characteristics of Microwave and High-Frequency In-Liquid Plasma in Water Applied Physics Express 1046002

[28] Sakaguchi N, Miyake M, Watanabe S and Takahashi H 2011 EELS and Ab-Initio Study of Faceted CSL Boundary in Silicon MATERIALS TRANSACTIONS 52 276-9

[29] Yutaka Y, Norihito S, Seiichi W and Takahiko K 2011 Self-Organized Two-Dimensional Vidro-Nanodot Array on Laser-Irradiated Si Surface Applied Physics Express 4055202

[30] Seidel H, Csepregi L, Heuberger A and Baumgärtel H 1990 Anisotropic Etching of Crystalline Silicon in Alkaline Solutions: I . Orientation Dependence and Behavior of Passivation Layers Journal of The Electrochemical Society 137 3612-26

[31] Glembocki O J, Stahlbush R E and Tomkiewicz M 1985 Bias - Dependent Etching of Silicon in Aqueous $\mathrm{KOH}$ Journal of The Electrochemical Society 132 145-51

[32] Polatides C, Dortsiou M and Kyriacou G 2005 Electrochemical removal of nitrate ion from aqueous solution by pulsing potential electrolysis Electrochimica Acta $\mathbf{5 0}$ $5237-41$

[33] McDowell M T, Lee S W, Harris J T, Korgel B A, Wang C, Nix W D and Cui Y 2013 In 
Situ TEM of Two-Phase Lithiation of Amorphous Silicon Nanospheres Nano Letters 13 758-64 